\section{Check for updates}

Cite this: J. Mater. Chem. A, 2021, 9, 24406

Received 23rd July 2021

Accepted 23rd October 2021

DOI: $10.1039 / \mathrm{d} 1 \mathrm{ta0} 237 \mathrm{a}$

rsc.li/materials-a

\title{
Pt current collectors artificially boosting praseodymium doped ceria oxygen surface exchange coefficients $\dagger$
}

\begin{abstract}
Yuxi Ma, (D) ${ }^{\text {ab }}$ Theodore E. Burye (iD) ac and Jason D. Nicholas (iD *a
The chemical oxygen surface exchange coefficient $\left(k_{\mathrm{chem}}\right)$ values used to quantify and rank oxygen evolution reaction (OER) and oxygen reduction reaction (ORR) catalyst performance for hightemperature, oxygen-exchange-enabled devices (such as Solid Oxide Fuel Cells, Solid Oxide Electrolysis Cells, oxygen sensors, etc.) are often determined electrically, with the aid of precious metal current collectors. However, the curvature relaxation $(\kappa R)$ and Time-of-Flight Secondary Ion Mass Spectroscopy (ToF-SIMS) analyses performed here on Pulsed Laser Deposited thin films of the oxygen exchange catalyst $\operatorname{Pr}_{0.1} \mathrm{Ce}_{0.9} \mathrm{O}_{2-x}(\mathrm{PCO})$ show that unpolarized platinum current collectors dramatically improve the $k_{\text {chem }}$ of Si-contaminated PCO by reducing the Si concentration at the PCO surface and/or diffusing into the PCO; even for PCO thin films only exposed to mild temperatures of $500{ }^{\circ} \mathrm{C}$. This suggests that precious metal current collectors are likely responsible for some of the large $k_{\text {chem }}$ variation reported in the literature for "identical" materials tested under "identical" conditions.
\end{abstract}

\section{Introduction}

Solid Oxide Fuel Cells (SOFCs) are solid state chemical to electrical energy conversion devices that exhibit high power density, high energy density, high energy conversion efficiency, and fuel flexibility. ${ }^{1-4}$ In addition, SOFCs can be used in reverse as Solid Oxide Electrolysis Cells (SOECs) to store energy, produce chemicals, and/or generate fuels. ${ }^{4-7}$ Unfortunately, high system costs, high operating temperatures, and high degradation rates have complicated the commercial deployment of these Solid Oxide Cells (SOCs). ${ }^{4}$ With time however, it seems likely that improved materials will help lower these commercialization barriers. Since today's "State-of-the-Art" SOCs are typically limited by poor oxygen ion transport (1) through the bulk of the solid electrolyte, (2) across the solid electrolyte-solid electrode interface, and/or (3) across the solid electrode-gas phase interface, ${ }^{8}$ it seems likely that future material sets will feature increased bulk oxygen ion conductivities, reduced interfacial resistivities, and/or increased chemical oxygen surface exchange coefficients.

The chemical oxygen surface exchange coefficient, $k_{\mathrm{chem}}$, is commonly defined as:

\footnotetext{
${ }^{a}$ Michigan State University, Chemical Engineering and Materials Science Dept., East Lansing, MI 48824, USA. E-mail: jdn@msu.edu

${ }^{b}$ Contemporary Amperex Technology USA Inc, Rochester Hills, MI 48309, USA

${ }^{c}$ U.S. Army Combat Capabilities Development Command Ground Vehicle Systems Center, Warren, MI 48092, USA

$\dagger$ Electronic supplementary information (ESI) available. See DOI: 10.1039/d1ta06237a
}

$$
J=k_{\text {chem }}\left(C_{\mathrm{o}}-C_{\mathrm{s}}\right)
$$

where $J$ is the oxygen flux across a surface, $C_{\mathrm{o}}$ is the oxygen concentration just inside the material, and $C_{\mathrm{s}}$ is the oxygen concentration on the surface required to maintain equilibrium with the surrounding atmosphere. ${ }^{9}$ As such, $k_{\text {chem }}$ can be regarded as a "materials property" that can be used to rank a surface's ability to facilitate oxygen transport between a material's interior and the surrounding environment. For today's most common Mixed Ionic Electronic Conducting (MIEC) oxygen exchange catalysts, all of which have electronic transference numbers close to 1 , this ranking can be done through 1) a direct $k_{\text {chem }}$ comparison (assuming that the materials have similar lattice oxygen concentrations that vary similarly with oxygen partial pressure $\left(p_{\mathrm{O} 2}\right)$, as is often the case as shown in Fig. S1 of the ESI + ), or (2) through its official conversion into a near-open-circuit oxygen surface exchange resistance, $R_{\mathrm{s}}$, via the equation:

$$
R_{\mathrm{s}}=\frac{k_{\mathrm{B}} T}{4 e^{2} C_{\mathrm{o}} k_{\mathrm{o}}}
$$

where $k_{\mathrm{B}}$ is Boltzman's constant, $T$ is the temperature in Kelvin, $e$ is the elementary charge of an electron, $C_{\mathrm{o}}$ is the oxygen ion concentration just inside the material, and $k_{\mathrm{o}}$ is the oxide ion surface exchange rate constant (which is often approximated as the electrically-determined oxygen surface exchange coefficient, $k_{\mathrm{q}}$ (ref. 10)) defined as:

$$
k_{\mathrm{o}}=k_{\mathrm{chem}} / \gamma_{\mathrm{o}}
$$




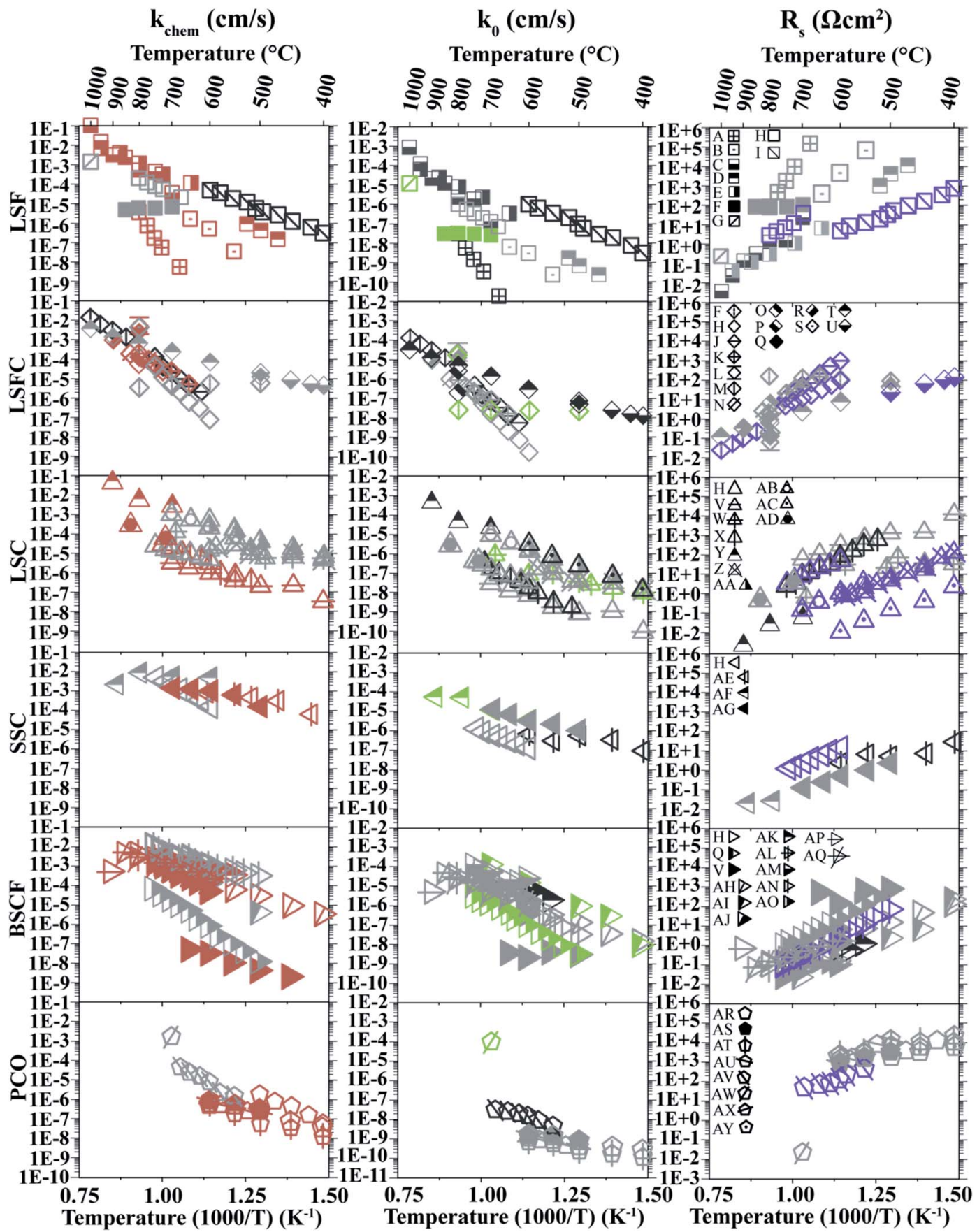

Fig. 1 Literature-reported oxygen surface exchange properties of $\mathrm{La}_{0.6} \mathrm{Sr}_{0.4} \mathrm{FeO}_{3-x}$ (LSF, squares), $\mathrm{La}_{0.6} \mathrm{Sr}_{0.4} \mathrm{Fe}_{0.8} \mathrm{Co}_{0.2} \mathrm{O}_{3-x}$ ( $\left(\mathrm{LSFC}_{1}\right.$, diamonds), $\mathrm{La}_{0.6} \mathrm{Sr}_{0.4} \mathrm{CoO}_{3-x}$ (LSC, up-pointing triangles), $\mathrm{Sm}_{0.5} \mathrm{Sr}_{0.5} \mathrm{CoO}_{3-x}$ (SSC, left-pointing triangles), $\mathrm{Ba}_{0.5} \mathrm{Sr}_{0.5} \mathrm{Co}_{0.8} \mathrm{Fe}_{0.2} \mathrm{O}_{3-x}$ (BSCF, right-pointing triangles) and $\operatorname{Pr}_{0.1} \mathrm{Ce}_{0.9} \mathrm{O}_{1.95-x}$ (PCO, pentagons) in air. Color denotes directly-measured values. Dark gray denotes values converted via eqn (2)(4) with data from the same study as the directly-measured value. Light gray denotes values converted via eqn (2)-(4) with $C_{0}$ and $\gamma_{0}$ values obtained from other studies (i.e. those shown in Fig. S1 of the ESI $\dagger$ ). Here, $k_{\circ}$ was assumed to be $\approx k_{\mathrm{q}}$, as commonly done in the literature ${ }^{10}$. The $\mathrm{ESI} \uparrow$ contains a description of the minor equations and the actual spreadsheets used to perform the oxygen surface exchange conversions. $\mathrm{A}=$ Mosleh et al. ${ }^{57} \mathrm{~B}=$ Søgaard et al. ${ }^{53} \mathrm{C}=$ Søgaard et al., ${ }^{113} \mathrm{D}=$ Yang et al., ${ }^{79} \mathrm{E}=$ ten Elshof et al., ${ }^{15} \mathrm{~F}=$ Armstrong et al. ${ }^{114} \mathrm{G}=$ Ishigaki et al., ${ }^{115} \mathrm{H}=$ Baumann et al. ${ }^{116} \mathrm{I}=$ Tripkovic et al. ${ }^{36} \mathrm{~J}=$ Plonczak et al. ${ }^{60} \mathrm{~K}=$ Bouwmeester et al.. ${ }^{117} \mathrm{~L}=\mathrm{Cox}$-Galhorta and McIntosh. ${ }^{35} \mathrm{M}=\mathrm{Dalslet}$ et al. ${ }^{13} \mathrm{~N}=$ Huang et al., ${ }^{118} \mathrm{O}=$ Lane et al., ${ }^{119} \mathrm{P}=$ Li et al., ${ }^{120} \mathrm{Q}=$ Ried et al., ${ }^{121} \mathrm{R}=$ Wang et al., ${ }^{122} \mathrm{~S}=$ Chater et al., ${ }^{123} \mathrm{~T}=\mathrm{Steele}$ and Bae, ${ }^{124} \mathrm{U}=\mathrm{Simrick}$ et al., ${ }^{62} \mathrm{~V}$ $=$ Moreno et al., ${ }^{125} \mathrm{~W}=$ Berenov et al. ${ }^{126} \mathrm{X}=$ Egger et al., ${ }^{127} \mathrm{Y}=\mathrm{S} \varnothing$ gaard et al., ${ }^{128} \mathrm{Z}=$ Januschewsky et al., ${ }^{28} \mathrm{AA}=\mathrm{Siebenhofer} \mathrm{et} \mathrm{al.,}{ }^{40} \mathrm{AB}=\mathrm{Adler},{ }^{129}$ $\mathrm{AC}=$ Hayd et al. ${ }^{10} \mathrm{AD}=$ Preis et al., ${ }^{43} \mathrm{AE}=$ Yeh et al., ${ }^{130} \mathrm{AF}=$ Fullarton et al., ${ }^{131} \mathrm{AG}=\mathrm{Fu}$ et al.,${ }^{132} \mathrm{AH}=\mathrm{Burriel}$ et al., ${ }^{56} \mathrm{Al}=\mathrm{Wang}$ et al.. ${ }^{133} \mathrm{AJ}=$ Bucher et al. ${ }^{134} \mathrm{AK}=$ Bucher et al., ${ }^{135} \mathrm{AL}=$ Chen and Shao, ${ }^{136} \mathrm{AM}=$ Girdauskaite et al. ${ }^{137} \mathrm{AN}=$ Baumann et al., ${ }^{138} \mathrm{AO}=\mathrm{Wang}$ et al. ${ }^{139}$, $\mathrm{AP}=$ Falkenstein et al., ${ }^{44} \mathrm{AQ}=$ Lohne et al., ${ }^{140} \mathrm{AR}=$ Nicollet et al. ${ }^{141} \mathrm{AS}=$ Nicollet et al. ${ }^{51} \mathrm{AT}=$ Chen et al. ${ }^{102} \mathrm{AU}=\mathrm{Ma}$ and Nicholas, ${ }^{75} \mathrm{AV}=\mathrm{Chen}$ et al., ${ }^{90}$ $\mathrm{AW}=$ Simons et al. ${ }^{61} \mathrm{AX}=$ Zhao et al., ${ }^{105} \mathrm{AY}=$ Chen et al. ${ }^{102}$ Bold studies were performed on thin films, italic studies were performed on loose or partially sintered powders, and unformatted studies were performed on bulk pellets with relative densities $>92 \%$. 
where $\gamma_{o}$ is the thermodynamic factor for oxygen defined as: $:^{11-15}$

$$
\gamma_{\mathrm{o}}=\frac{1}{2} \frac{\partial \ln \left(p \mathrm{O}_{2}\right)}{\partial \ln \left(C_{\mathrm{o}}\right)}
$$

A material's oxygen surface exchange properties (i.e. a material's $k_{\text {chem }}, k_{\mathrm{o}}, k_{\mathrm{q}}, R_{\mathrm{s}}$ etc.) can also be combined with SOC structure-property-performance models ${ }^{16-18}$ to predict SOC electrode polarization resistances ${ }^{19-21}$ and/or identify optimal SOC electrode microstructures. ${ }^{22}$ Other devices (such as solar thermochemical cells, ${ }^{23}$ oxide memristors, ${ }^{24}$ oxygen separation membranes, ${ }^{25}$ catalytic converters ${ }^{26}$ oxygen sensors, ${ }^{27}$ etc.) can also have their performance and/or efficiency impacted by the oxygen surface exchange properties of the materials within them.

However, before the scientific community can effectively engineer oxygen surface exchange coefficients for improved device performance, it must first figure out how to reliably measure them. Specifically, Fig. 1 shows that, even for the most common MIEC materials, huge $k_{\text {chem }}, k_{\mathrm{o}}$ and $R_{\mathrm{S}}$ variations exists in literature for "identical" materials under "identical" conditions. For instance, in Fig. 1 there is $a>1000$ times variation in the extrapolated $700{ }^{\circ} \mathrm{C} \operatorname{Pr}_{0.1} \mathrm{Ce}_{0.9} \mathrm{O}_{2-x}$ (PCO) $k_{\text {chem }}$ values, $a>10000$ times variation in the measured $650{ }^{\circ} \mathrm{C} \mathrm{La}_{0.6} \mathrm{Sr}_{0.4}{ }^{-}$ $\mathrm{FeO}_{3-x}$ (LSF) $k_{\text {chem }}$ values, and $a>100000$ times variation in the measured $500{ }^{\circ} \mathrm{C} \mathrm{Ba}_{0.6} \mathrm{Sr}_{0.4} \mathrm{Co}_{0.8} \mathrm{Fe}_{0.2} \mathrm{O}_{3-x}$ (BSCF) $k_{\text {chem }}$ values.

The reasons for these oxygen surface exchange property variations are manifold. For instance, previous studies have shown that systematic differences in film crystallinity, ${ }^{28,29}$ grain size, ${ }^{30}$ surface orientation, ${ }^{31-34}$ surface chemistry, ${ }^{35-39}$ and/or surface gas phase adsorbates ${ }^{34,40,41}$ can all impact a material's measured oxygen surface exchange properties. Experimental complications such as poor gas phase mixing, ${ }^{42}$ noninstantaneous atmospheric switching times ${ }^{43}$ and/or large amounts of sample oxygen release that can undesirably alter the atmospheric $p_{\mathrm{O} 2}$ (ref. 44) can also produce $k_{\text {chem }}$ variations.

However, despite the fact that precious metal surface additions are well known to improve the performance of the MIEC materials used as SOC electrodes, oxygen sensors, vehicular catalytic converters etc. ${ }^{45-48}$ an examination of how current collectors (especially the precious metal current collectors commonly used in the existing oxygen surface exchange literature ${ }^{36,40,49-62}$ ), affect oxygen surface exchange properties is less clear. This uncertainty is perpetuated by the fact that (1) today's most-common $k_{\text {chem }}, k_{\mathrm{o}}, k_{\mathrm{q}}$, and $R_{\mathrm{s}}$ measurement techniques (i.e. Electrical Conductivity Relaxation (ECR) and Electrochemical Impedance Spectroscopy (EIS)) require the electrical polarization of a current collector, and (2) many ECR and EIS studies do not include descriptions of the current collector microstructure, materials, thickness, pattern geometry, and/or electrical-polarization used to perform the oxygen surface exchange measurements. This is problematic because electrically-polarized current collectors could alter oxygen exchange through (1) the enhanced oxygen exchange properties some precious metals have been shown to catalyze at metalMIEC-air interfaces, ${ }^{47,63-65}(2)$ the chemical gettering of surfacesegregated MIEC ions/impurities that some current collecting materials are known to possess, ${ }^{66}$ (3) current collector coefficient of thermal expansion (CTE) mismatch stress induced alterations in the point defect and/or surface chemistry that some mechano-chemically-active MIECs are known to exhibit, ${ }^{67,68}$ (4) electric-field induced alterations in the point defect, surface chemistry, and/or metal-MIEC-air triple-phaseboundary widths that are known to occur in some MIECs, ${ }^{63,68-70}$ etc.

Although a few studies to the contrary exist, ${ }^{71}$ many more studies have found that precious metal surface decoration can significantly alter a material's measured oxygen surface exchange properties. For instance, ECR measurements by Egger and Sitte ${ }^{72}$ demonstrated that a thin layer of silver increased the $600{ }^{\circ} \mathrm{C} k_{\text {chem }}$ of $\mathrm{La}_{2} \mathrm{NiO}_{4}$ by an order of magnitude, and Zhang et $a .^{32}$ observed similar ECR $k_{\text {chem }}$ improvements for lanthanum strontium manganate decorated with platinum or palladium nanoparticles. EIS and oxygen isotope exchange depth profiling experiments by Sahibzada et al. ${ }^{73}$ showed that palladium surface decoration decreased the $700{ }^{\circ} \mathrm{C} k_{\mathrm{o}}$ of $\mathrm{La}_{0.6^{-}}$ $\mathrm{Sr}_{0.4} \mathrm{Fe}_{0.8} \mathrm{Co}_{0.2} \mathrm{O}_{3-x}$ (LSFC) by an order of magnitude but improved the electrochemical performance of LSFC at lower temperatures. Similarly, microelectrode EIS measurements performed by Riedl et $a .^{74}$ showed that platinum surface decoration either increased or decreased the $R_{\mathrm{S}}$ of $\mathrm{La}_{0.6} \mathrm{Sr}_{0.4^{-}}$ $\mathrm{FeO}_{3-x}$ (LSF) by up to $\sim 100$ times depending on the $p_{\mathrm{O}_{2}}$. Further, Ma and Nicholas ${ }^{75}$ found that the $600{ }^{\circ} \mathrm{C}$ PCO $k_{\text {chem }}$ values obtained from current-collector-free curvature relaxation $(\kappa R)$ and current-collector-free optical transmission relaxation (OTR) experiments were identical, but more than 10-100 times lower than those obtained from $k_{\text {chem }}$ techniques utilizing precious metals. Similarly, simultaneous $\sim 300-600 \quad{ }^{\circ} \mathrm{C}$ measurements by Perry and coworkers ${ }^{59,76}$ on strontium titanium ferrite thin films showed that roughly identical $k_{\text {chem }}$ values were obtained from OTR and in-plane ECR measurements utilizing current collectors that only covered a small portion of the MIEC surface, but that $\sim 10$ times higher $k_{\text {chem }}$ values were obtained via through-sample EIS measurements utilizing current collectors covering a large portion of the MIEC surface.

Despite these reports, precious metal current collectors are still being actively used to measure the oxygen surface exchange properties of MIEC materials. ${ }^{36,49-60}$ Hence, the first objective of this work was to dramatically demonstrate the role that even minute amounts of unpolarized precious metals can have on

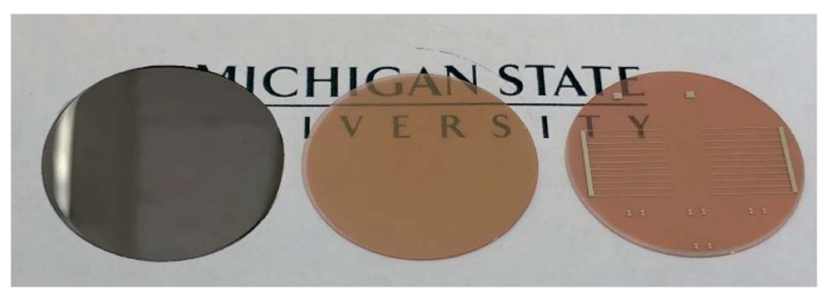

Fig. 2 A completely Pt-covered PCO|YSZ sample (left), an uncovered $\mathrm{PCO}$ YSZ sample (middle), and a partially Pt-covered PCO|YSZ sample (right). Note, each sample was $25.4 \mathrm{~mm}$ in diameter. 
the $k_{\text {chem }}$ of MIEC materials. The second objective of this work was to go beyond the aforementioned past studies and identify any local chemistry changes likely responsible for the observed $k_{\text {chem }}$ alteration. These objectives were achieved by pairing (1) the remarkable ability of the curvature relaxation technique to obtain direct $k_{\text {chem }}$ measurements on PCO thin films that were either uncovered, partially Pt-covered, or completely Pt-covered, with (2) Time-of-Flight Secondary Ion Mass Spectrometry (ToFSIMS) analyses of the sample chemistry before and after curvature relaxation.

\section{Experimental methods}

Here, PCO thin films were produced by Pulsed Laser Deposition (PLD), optionally coated with one of the platinum current collector geometries shown in Fig. 2, and tested via curvature relaxation $(\kappa R)$.

\subsection{Sample fabrication}

Prior to thin film deposition, $25.4 \mathrm{~mm}$ diameter, one-sidepolished, 200-micron-thick, (100)-oriented $\left(\mathrm{Y}_{2} \mathrm{O}_{3}\right)_{0.095}\left(\mathrm{ZrO}_{2}\right)_{0.905}$ (YSZ) single crystal substrates (Crystec $\mathrm{GmbH}$, Berlin, Germany) were air-annealed at $1450{ }^{\circ} \mathrm{C}$ for $20 \mathrm{~h}$ utilizing $5{ }^{\circ} \mathrm{C} \min ^{-1}$ nominal heating and cooling rates to remove any residual stress within them. This wafer annealing schedule was chosen because it had previously been shown capable of reducing the curvature changes observed upon heating these YSZ wafers from 25 to $700{ }^{\circ} \mathrm{C}$ to less than 0.005 $\mathrm{m}^{-1}$ (so that residual stress changes would not obscure the $\sim 0.002 \mathrm{~m}^{-1}$ curvature changes caused by film reduction or oxidation at a single, constant temperature). ${ }^{75}$ In addition, $\sim 94 \%$ dense $\operatorname{Pr}_{0.1} \mathrm{Ce}_{0.9} \mathrm{O}_{2-\delta}$ PLD targets were produced from PCO powder fabricated via the glycine nitrate combustion (GNC) method. ${ }^{77}$ This GNC process was conducted by first dissolving 99.9\% pure cerium nitrate (Strem Chemicals, Newburyport MA), 99.9\% pure praseodymium nitrate (Strem Chemicals, Newburyport MA), and 99\% pure glycine (Millipore Sigma, Burlington, MA) in 18.2 M $\Omega$ water (Millipore Sigma, Burlington, MA) at a $1: 1$ glycine : nitrate molar ratio using a Teflon coated stir bar (Fischer Scientific, Pittsburgh, PA) in a Pyrex beaker (Fischer Scientific, Pittsburgh, PA). The resulting solutions were then ignited over a hotplate in a stainless-steel reaction vessel (Polar Ware, Kiel, WI). To remove unreacted glycine, the resulting powder was calcined in a $99.8 \%$ pure alumina crucible (CoorsTek, Golden, CO) at $1000{ }^{\circ} \mathrm{C}$ in air for 1 hour using $5{ }^{\circ} \mathrm{C} \min ^{-1}$ nominal heating and cooling rates. The calcined powder was then uniaxially compacted to $\sim 63 \mathrm{MPa}$ in a $38 \mathrm{~mm}$ stainless-steel die (MTI, Richmond, CA) and sintered at $1450{ }^{\circ} \mathrm{C}$ for $20 \mathrm{~h}$ in air using nominal $3^{\circ} \mathrm{C} \mathrm{min}{ }^{-1}$ heating and $10{ }^{\circ} \mathrm{C} \mathrm{min}^{-1}$ cooling rates. The resulting sintered target was then ground down to $25 \mathrm{~mm}$ diameter and $2.5 \mathrm{~mm}$ thick using 240 grit SiC sandpaper and bonded with silicone to a $\sim 2.5 \mathrm{~mm}$ thick, $25 \mathrm{~mm}$ diameter copper backing.

PCO PLD thin films were produced from the aforementioned target by depositing $\sim 265 \mathrm{~nm}$ of PCO onto $700{ }^{\circ} \mathrm{C}$-preheated YSZ wafers within 30 mTorr of oxygen using the PLD/MBE
2300 system (PVD Products, Inc) at the Northwestern University PLD User Facility. PLD was conducted using a $100 \mathrm{~mm}$ target-to-substrate distance and $15000,10 \mathrm{~Hz}, 200 \mathrm{~mJ}, 248 \mathrm{~nm}$ $\mathrm{KrF}$ excimer laser pulses. All the $\mathrm{PCO} \mid \mathrm{YSZ}$ samples reported here were (1) cooled to room temperature at $10{ }^{\circ} \mathrm{C} \mathrm{min}{ }^{-1}$ upon the completion of PCO deposition, (2) produced consecutively during a single PLD session, and (3) stored within individual polypropylene wafer containers when not undergoing subsequent processing or characterization. After thin film deposition, each PCO|YSZ sample had its oxygen vacancy defect concentration re-equilibrated with air via an hour-long $1100{ }^{\circ} \mathrm{C}$ hold utilizing nominal $3{ }^{\circ} \mathrm{C} \mathrm{min}^{-1}$ heating and cooling rates.

To produce patterned platinum current collectors covering $\sim 2.7 \%$ of the PCO geometric surface area (such as those for the "partially Pt-covered PCO|YSZ samples shown on the right-hand side of Fig. 2) some of the $1100{ }^{\circ} \mathrm{C}$ re-equilibrated PCO $\mid$ YSZ samples were subjected to an acetone rinse, a methanol rinse, a deionized water rinse, nitrogen gas drying, a 5-10 minute excursion to $115{ }^{\circ} \mathrm{C}, 10$ seconds of $700 \mathrm{rpm}$ rotation in a spin coater, and finally 30 seconds of $3000 \mathrm{rpm}$ rotation in a spin coater. Next, the exposed PCO surfaces of these samples were covered with Photoresist S1813 (Microchem Corp, Westborough, MA) by slowing the PCO|YSZ sample rotation to $700 \mathrm{rpm}$, dripping $\sim 50 \mu \mathrm{L}$ of photoresist solution onto the $\mathrm{PCO} \mid$ YSZ sample, removing the PCO|YSZ sample from the spin coater, and baking the spin-coated sample for $1 \mathrm{~min}$ at $115{ }^{\circ} \mathrm{C}$. Current collector patterns were then introduced into the photoresist via UV curing in a Karl Suss MJB3 mask aligner (SUSS MicroTec SE, Garching, Germany) using a positive mask (Photoscience Inc, Lexington, KY) and 274 watts of $250 \mathrm{~nm}$ light for 90 seconds. The UV-exposed portion of the photoresist was then removed by exposing it to photoresist developer MF319 (Microchem Corp, Westborough, MA) for 45 seconds, rinsing it with deionized water, and then baking it in air at $115{ }^{\circ} \mathrm{C}$ for 5 min. The samples were then placed in an Axiss PVD System (Kurt J. Lesker, Jefferson Hills, PA), and the total chamber pressure was pumped down to $10^{-6}$ torr. After backfilling with Ar gas until the total chamber pressure was 20 mTorr, and after initiating $30 \mathrm{rpm}$ of sample rotation, platinum (from a 99.95\% pure Pt target) was sputtered onto the sample surface for 1 minute using $200 \mathrm{~W}$ of power. After removal from the sputtering chamber, these samples were dipped in acetone and then rinsed in isopropanol to remove the photoresist.

To produce "completely" Pt-covered PCO|YSZ samples such as those shown in the left side of Fig. 2 (i.e. those where $100 \%$ of the geometric PCO surface area was covered with $89 \%$ dense $^{78}$ Pt films), some PCO|YSZ samples were placed in the aforementioned Axiss PVD system and subjected to the same platinum sputtering conditions used for the partially Pt-covered PCO|YSZ samples. However, these completely Pt-covered samples were not subject to the solvent cleaning, photoresist application, UV curing, or photoresist removal processes needed for the partially Pt-covered samples.

To make sure the $\kappa R$ signal of the completely Pt-covered PCO|YSZ samples came from oxygen exchange into/out of the PCO (instead of the Pt), a bare YSZ wafer was completely covered 
with platinum using the same procedures as those used for the completely Pt-covered PCO|YSZ samples.

\subsection{Oxygen surface exchange measurements}

Here, thin film PCO oxygen surface exchange coefficient measurements were performed using the $\kappa R$ method described, and derived, previously in the literature. ${ }^{75,79-82}$ In brief, the curvature relaxation techniques determines $k_{\text {chem }}$ from the PCO volume changes accompanying small, isothermal, $p_{\mathrm{O}_{2}}$-induced changes in the oxygen nonstoichiometry $(\Delta \delta)$ that occur in PCO above $\sim 400{ }^{\circ} \mathrm{C}$ in air via the reaction: $:^{75,83-85}$

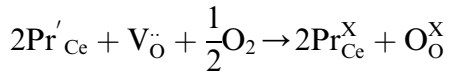

Assuming that as this mechano-chemically-active defect reaction proceeds (1) the oxygen-exchange-active thin film remains well bonded to an oxygen-exchange-inactive substrate, (2) the film and substrate only deform in a linear elastic manner, (3) the film is more than $\sim 500$ times thinner than the substrate but is thick enough to ensure that its volume changes bend the wafer in a detectable manner, (4) the film thickness is at least $\sim 500$ times lower than the film materials characteristic thickness $\left(L_{\mathrm{C}}=D_{\text {chem }} / k_{\text {chem }}\right.$ where $D_{\text {chem }}$ is the chemical diffusion coefficient) to ensure that the sample response is only controlled by surface exchange and not partially or fully controlled by oxygen diffusion in the bulk of the film, and (5) the $p_{\mathrm{O}_{2}}$ step size is small enough to ensure that (a) the oxygen surface exchange process remains linear, and (b) the resulting change in oxygen nonstoichiometry $(\Delta \delta)$ is small enough to ensure that the film strain $\left(\varepsilon_{\mathrm{C}}\right)$ can be described by:

$$
\varepsilon_{\mathrm{C}}=\left.\frac{\Delta l}{l}\right|_{T}=\alpha_{\mathrm{C}} \Delta \delta
$$

where $\alpha_{\mathrm{C}}$ is the chemical expansion coefficient, the PCO oxygen surface exchange coefficient can be mathematically extracted from how quickly the PCO $\mid$ YSZ sample curvature equilibrates to a new $p_{\mathrm{O}_{2}}$ by fitting the observed curvature relaxation to the following solution to Fick's second law: ${ }^{9}$

$$
\frac{\kappa-\kappa_{0}}{\kappa_{\infty}-\kappa_{0}}=1-\exp \left(-\frac{k_{\text {chem }} t}{h_{\mathrm{f}}}\right)
$$

where $\kappa$ is the instantaneous sample curvature, $\kappa_{0}$ is the sample curvature before the relaxation, $\kappa_{\infty}$ is the sample curvature after the relaxation, $t$ is time, and $h_{\mathrm{f}}$ is the film thickness. In addition to being a non-contact, in situ thin film $k_{\text {chem }}$ measurement technique that works with, or without, overlying current collecting layers, the $\kappa R$ technique has the benefit that no specific film or substrate materials property values are required to obtain accurate thin film $k_{\text {chem }}$ values via eqn (7) (so long as the film and substrate have isotropic in-plane mechanical properties, as was the case here).

To determine if multiple processes with different time constants (or different rates of the same process in different parts of the sample) were active, all curvature data was replotted

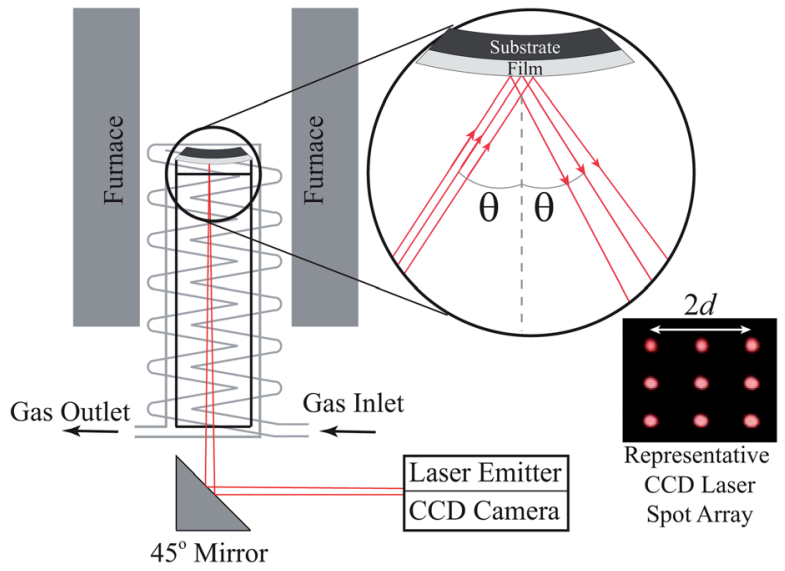

Fig. 3 Schematic of the Multi-beam Optical Stress (MOS) sensor setup used to perform the curvature relaxation oxygen surface exchange coefficient measurements reported here. Reprinted from Nicholas, ${ }^{81}$ with permission from Elsevier.

to search for slope changes in $\ln \left[1-\frac{\kappa-\kappa_{0}}{\kappa_{\infty}-\kappa_{0}}\right] v s$. time plots during each relaxation, as has been done previously. ${ }^{31,79,86-88}$

Fig. 3 shows a schematic of the controlled atmosphere multibeam optical stress sensor setup used to perform the $\kappa R$ measurements reported here (see Nicholas ${ }^{\mathbf{8 1}}$ for the exact dimensions). In preparation for $\kappa R$ experiments, each PCO $\mid$ YSZ sample was placed atop the central quartz support tube shown in Fig. 3, covered with the controlled-atmosphere gaspreheating manifold shown in Fig. 3, heated to $500{ }^{\circ} \mathrm{C}$ at $5{ }^{\circ} \mathrm{C} \mathrm{min}{ }^{-1}$, and held at $500{ }^{\circ} \mathrm{C}$ for 1 hour in air to equilibrate and homogenize the PCO oxygen vacancy concentration. Then, the uncovered, partially Pt-covered, and completely Pt-covered PCO|YSZ samples were measured in $25{ }^{\circ} \mathrm{C}$ increments from 675 to $725{ }^{\circ} \mathrm{C}, 500$ to $725{ }^{\circ} \mathrm{C}$, and 500 to $425{ }^{\circ} \mathrm{C}$, respectively, after holding for at least 30 minutes at each temperature to promote thermal equilibrium. Curvature relaxations were triggered by switching the $p_{\mathrm{O}_{2}}$ around each sample from $100 \mathrm{sscm}$ of $0.21\left(21 \% \mathrm{O}_{2}-79 \% \mathrm{Ar}\right.$, i.e. synthetic air) to $100 \mathrm{sccm} 0.021$ (2.1\% $\mathrm{O}_{2}-97.9 \%$ Ar, i.e. 10 times diluted synthetic air) using a four-way valve. Since the same synthetic gas mixtures were used to test all the samples, atmospheric impurity content differences should not have to contributed to the observed differences in sample behavior. As shown in Fig. S2-S4 of the ESI, $\uparrow$ each sample was allowed to re-equilibrate at each $p_{\mathrm{O}_{2}}$ for at least 5 times the characteristic relaxation time (to allow for reliable $\kappa R$ fitting, as explained in den Otter et al.). ${ }^{89}$ Only $k_{\text {chem }}$ values that were not reactor flush time limited (i.e. those where switching between two $100 \mathrm{sccm}$ gas flows or between two 300 sccm gas flows yielded the same $k_{\text {chem }}$ values) were reported here.

\subsection{Additional sample characterization}

To evaluate PCO thin film phase purity, X-Ray Diffraction (XRD) was performed in room temperature air from 20 to $80^{\circ}$ with a $0.01^{\circ}$ step size and a $1 \mathrm{~s}$ per step dwell time using unfiltered $\mathrm{Cu}$ 
$\mathrm{k}_{\alpha}$ radiation from a SmartLab diffractometer (Rigaku, The Woodlands, TX) operated at $44 \mathrm{kV}$ and $40 \mathrm{~mA}$ with $10 \mathrm{~mm}$-wide detector and source slits.

To evaluate PCO thin film surface composition, X-Ray Photoelectron Spectroscopy (XPS) was performed at room temperature and $10^{-9}$ torr on uncovered PCO|YSZ samples after (1) post-deposition re-equilibration in air and (2) after curvature relaxation. XPS was performed using the $\mathrm{Al} \mathrm{K} \alpha \mathrm{X}$-ray radiation inside a Phi 5600 XPS (PerkinElmer, Waltham, MA). XPS survey scans were collected with a step size of $0.4 \mathrm{eV}$ and a pass energy of $187.5 \mathrm{eV}$. XPS peak positions were calibrated with the carbon $1 \mathrm{~s}$ peak at $284.8 \mathrm{eV}$. Due to concerns that the vacuum encountered during XPS analysis might alter the PCO oxygen vacancy concentration, the samples used for XPS analyses were not used for $\kappa R$ experiments.

To evaluate film thickness, Scanning Electron Microscopy (SEM) was performed on fractured PCO|YSZ samples coated with $\sim 5 \mathrm{~nm}$ of Ti and imaged using a TESCAN MIRA3 Field Emission SEM (Tescan, Brno, Czechia).

To evaluate PCO thin film bulk composition, PCO|YSZ samples were analyzed via ToF-SIMS depth profiling conducted by EAG Labs (East Windsor, NJ, USA). The absolute concentrations of $\mathrm{Zr}, \mathrm{Y}$, and $\mathrm{O}$ in the films were calculated from the relative concentrations produced by SIMS by setting the SIMSdetected concentrations in the bulk of the YSZ substrate equal to those found in $\left(\mathrm{Y}_{2} \mathrm{O}_{3}\right)_{0.095}\left(\mathrm{ZrO}_{2}\right)_{0.905}$. Likewise, the absolute concentrations of Pr and Ce were calculated from the measured SIMS profiles by offsetting each Pr and Ce SIMS profile until the $\mathrm{Pr}$ and $\mathrm{Ce}$ concentrations in the interior of the film equaled those found in $\mathrm{Pr}_{0.1} \mathrm{Ce}_{0.9} \mathrm{O}_{2}$. Likewise again, the Pt concentration profiles were offset until those in the Pt current collector equaled those found in dense Pt metal. In contrast, a single $\mathrm{Ta}_{2} \mathrm{O}_{5}$ standard with a known amount of $\mathrm{Si}$ was used to estimate the Si concentrations in all the PCO films, assuming that the SIMS matrix effects in $\mathrm{Ta}_{2} \mathrm{O}_{5}$ and PCO were similar. Even if this assumption was incorrect and as a result introduced errors in the absolute Si concentration values, the fact that the same Si calibration, SIMS collection settings, and SIMS equipment were used for all the samples suggests that any relative Si concentration differences between the samples, and within each sample, should be valid.

\section{Results and discussion}

Fig. 4 shows representative XRD scans indicating that only crystalline, fluorite-structured PCO and crystalline, fluoritestructured YSZ peaks were present in the PCO $\mid$ YSZ samples. Consistent with previous literature reports, ${ }^{75,90-95}$ all the PCO films here exhibited (100) preferred orientation, consistent with the (100) oriented YSZ substrates they were grown upon.

Fig. 5 shows representative XPS scans indicating that the sample fabrication procedures used here produced "clean" PCO surfaces containing only Ce, Pr and O. No Si, Zr, Y or any other element was found in any of the XPS scans, even for uncovered PCO $\mid$ YSZ samples $\kappa R$ tested to $725^{\circ} \mathrm{C}$ in a Si-containing $\kappa R$ test rig known to vapor deposit $\mathrm{Si}$ on samples held for extended times at and above $600{ }^{\circ} \mathrm{C} .{ }^{96}$ This suggests that any surface

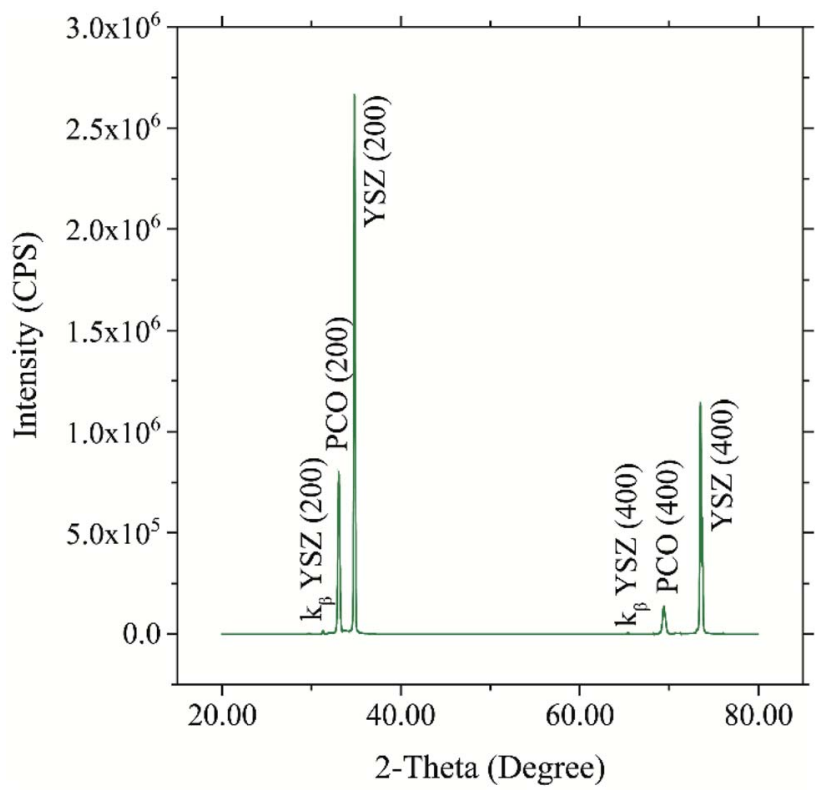

Fig. 4 XRD spectrum of an uncovered PCO|YSZ sample immediately before $\kappa R$ testing. Identical results (not shown) were obtained on uncoated samples analyzed after $\kappa R$ testing.

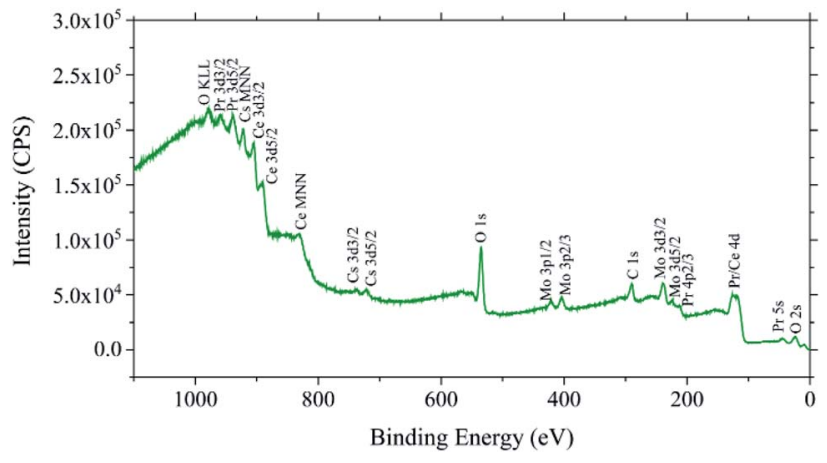

Fig. 5 XPS analysis of an uncovered PCO|YSZ sample immediately before $\kappa R$ testing. Note, the Mo peaks here are from the Mo XPS sample retaining mesh. Identical results (not shown) were obtained on uncoated PCO|YSZ samples analyzed after $\kappa R$ testing.

impurities in the PCO|YSZ samples here were present in amounts below the $\sim 1$ atomic percent XPS detection limit. ${ }^{97}$

Fig. S2-S4 of the ESI $\uparrow$ show representative curvature relaxation data for the uncovered, partially Pt-covered, and completely Pt-covered PCO|YSZ samples. These plots show that all the PCO|YSZ samples here exhibited reproducible equilibrium stress levels and oxygen surface exchange constants with $p_{\mathrm{O}_{2}}$ cycling. Further, as indicated by the linear nature of the $\ln \left[1-\frac{\kappa-\kappa_{0}}{\kappa_{\infty}-\kappa_{0}}\right]$ data during the portion of time each sample was equilibrating to a new $p_{\mathrm{O}_{2}}$, only a single oxygen exchange process was active for all the measured samples. The small deformations involved, the mechano-chemical inactivity of YSZ under the conditions used here, ${ }^{98}$ the chemical compatibility of 
YSZ and ceria under the conditions used here, ${ }^{99}$ a $h_{\mathrm{f}} / h_{\mathrm{S}}<0.002$, a $h_{\mathrm{f}}<0.0001 \times L_{\mathrm{C}}$ (based on the reported $450-725{ }^{\circ} \mathrm{C}$ PCO $L_{\mathrm{C}}$ values, ${ }^{\mathbf{9 0}} D_{\text {chem }}$ activation energies ${ }^{\mathbf{1 0 0 , 1 0 1}}$ and $k_{\text {chem }}$ activation energies ${ }^{51,75,90,102}$ ), and the reproducible curvature behavior with $p_{\mathrm{O}_{2}}$ switching for all the $\mathrm{PCO} \mid \mathrm{YSZ}$ samples tested here and shown in Fig. S5 of the ESI, $\uparrow$ ensured that all the assumptions needed to ensure the validity of eqn (7) were met.

Fig. 6 shows that covering either $\sim 2.7 \%$ or $100 \%$ of the PCO surface with unpolarized Pt current collectors significantly boosted the PCO oxygen surface exchange coefficient. Further, uncovered PCO|YSZ samples measured at the beginning (green circles) and end (red triangles) of the $k_{\text {chem }}$ measurement series yielded identical $k_{\text {chem }}$ values, attesting to the high reproducibility of the sample fabrication and measurement procedures used here. Interestingly, compared to uncovered PCO|YSZ samples from $\mathrm{Ma}$ and Nicholas ${ }^{75}$ that were prepared in a different PLD chamber, grown at a lower temperature, and (unlike the present samples) alkaline etched to remove surfacesegregated impurities, the uncovered PCO|YSZ samples here had lower $k_{\text {chem }}$ values. However, the $\sim 0.6 \mathrm{eV}$ activation energies observed for the present study's uncovered PCO|YSZ samples were similar to those measured above $500{ }^{\circ} \mathrm{C}$ in the curvature relaxation measurements on uncovered PCO PLD thin films from Ma and Nicholas, ${ }^{75}$ the optical transmission relaxation measurements on uncovered PCO PLD thin films from

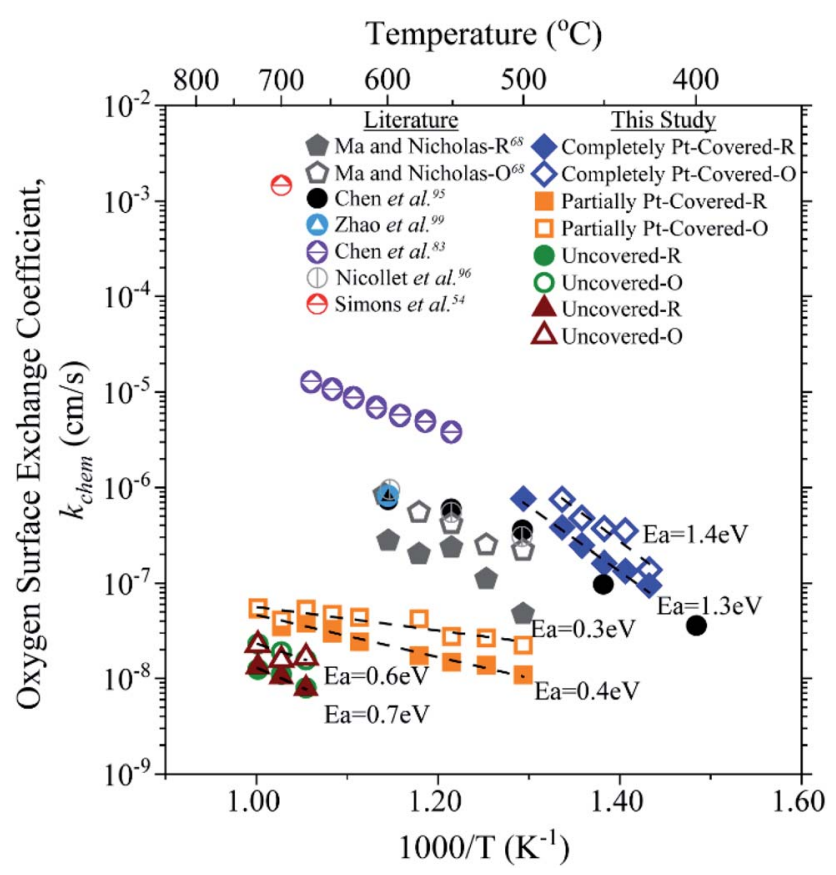

Fig. 6 Oxygen surface exchange coefficients for the uncovered PCO (green circles and red triangles), partially Pt-covered PCO (orange squares), and completely Pt-covered PCO (blue diamonds) thin films measured here, compared to the PCO literature. $51,61,75,90,102,105$ "- $R$ " denotes $k_{\text {chem }}$ values obtained upon reduction. "- $O$ " denotes $k_{\text {chem }}$ values obtained upon oxidation. Note, unlike the uncovered PCO $\kappa R$ samples from $\mathrm{Ma}$ and Nicholas, ${ }^{75}$ none of the samples here were alkaline etched to remove PCO surface impurities prior to $k_{\text {chem }}$ measurement.
Chen et al., ${ }^{\mathbf{1 0 2}}$ the electrochemical impedance spectroscopy measurements on Ag-paste-covered PCO PLD thin films from Chen et al.,$^{90}$ and the optical transmission relaxation measurements on uncovered PCO PLD thin films from Nicollet et al. ${ }^{\mathbf{5 1}}$ This suggests that the same rate-determining step for oxygen incorporation into $\mathrm{PCO}$ was active above $\sim 500{ }^{\circ} \mathrm{C}$ for all the PCO samples here and in the literature, even its rate was faster in some samples versus others.

In contrast, Fig. 6 shows that at temperatures less than $\sim 500{ }^{\circ} \mathrm{C}$, the completely Pt-covered PCO|YSZ samples (blue diamonds) had activation energies essentially double those of the uncoated PCO $\mid$ YSZ samples measured above $\sim 500{ }^{\circ} \mathrm{C}$. Similarly, although not mentioned by the authors, high sub$500{ }^{\circ} \mathrm{C}$ PCO activation energies of $\sim 1.3 \mathrm{eV}$ can also be seen in the optical transmission spectroscopy data of Chen et al. ${ }^{\mathbf{1 0 2}}$ on uncovered (i.e. Pt-free) PCO PLD thin films that transitioned to $k_{\text {chem }}$ activation energies of $\sim 0.5 \mathrm{eV}$ above $\sim 500{ }^{\circ} \mathrm{C}$. (Unfortunately, the exceeding-fast, low-temperature oxygen exchange kinetics of the completely Pt-covered PCO|YSZ samples meant that reactor flush time limitations prevented them from being measured above $500{ }^{\circ} \mathrm{C}$, when their $k_{\text {chem }}>1 \times 10^{-6} \mathrm{~cm} \mathrm{~s}^{-1}$ ). The fact that this previously unrecognized $k_{\text {chem }}$ activation energy transition was seen in Chen et al. 's ${ }^{\mathbf{1 0 2}}$ samples without platinum current collectors indicated that it is a general characteristic of PCO, and is not related to the absence or presence of precious metal current collectors. The observation of a higher activation energy at lower temperatures is the opposite of (1) what is commonly observed in other doped ceria compositions, ${ }^{103}$ and (2) what might be expected based on the idea that lower temperatures would de-activate higher activation energy barrier pathways for oxygen exchange into/out of a static

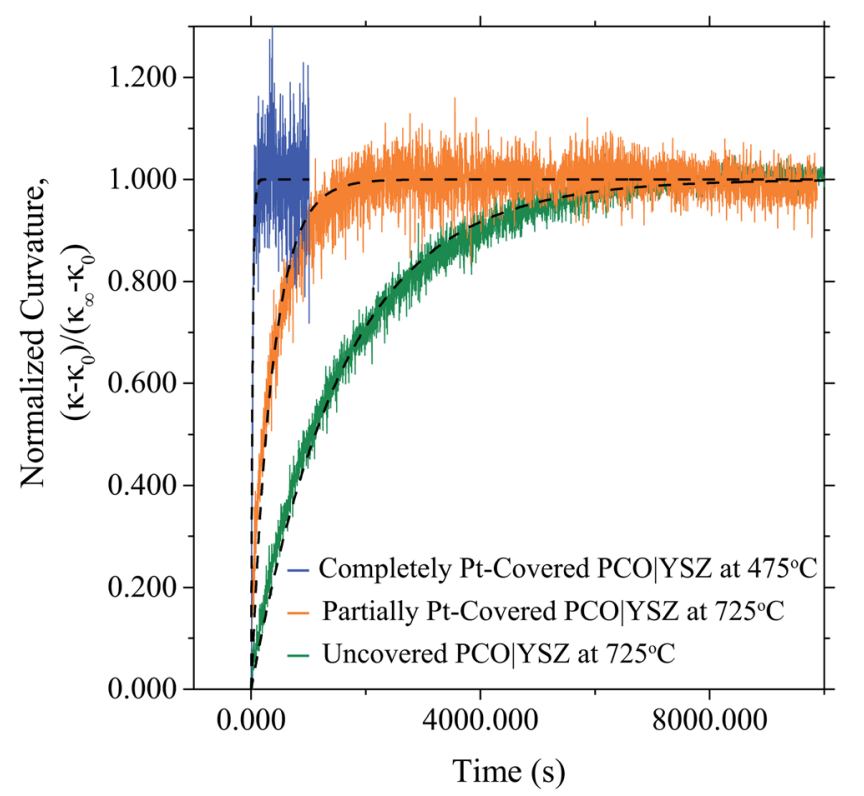

Fig. $7 \kappa R$ behavior of a completely Pt-covered PCO|YSZ sample at $475{ }^{\circ} \mathrm{C}$ compared to a partially Pt-covered PCO|YSZ sample at $725^{\circ} \mathrm{C}$ and an uncovered $\mathrm{PCO} \mid \mathrm{YSZ}$ sample at $725^{\circ} \mathrm{C}$. The dashed lines are eqn (7) fits to the data. 
a)

b)

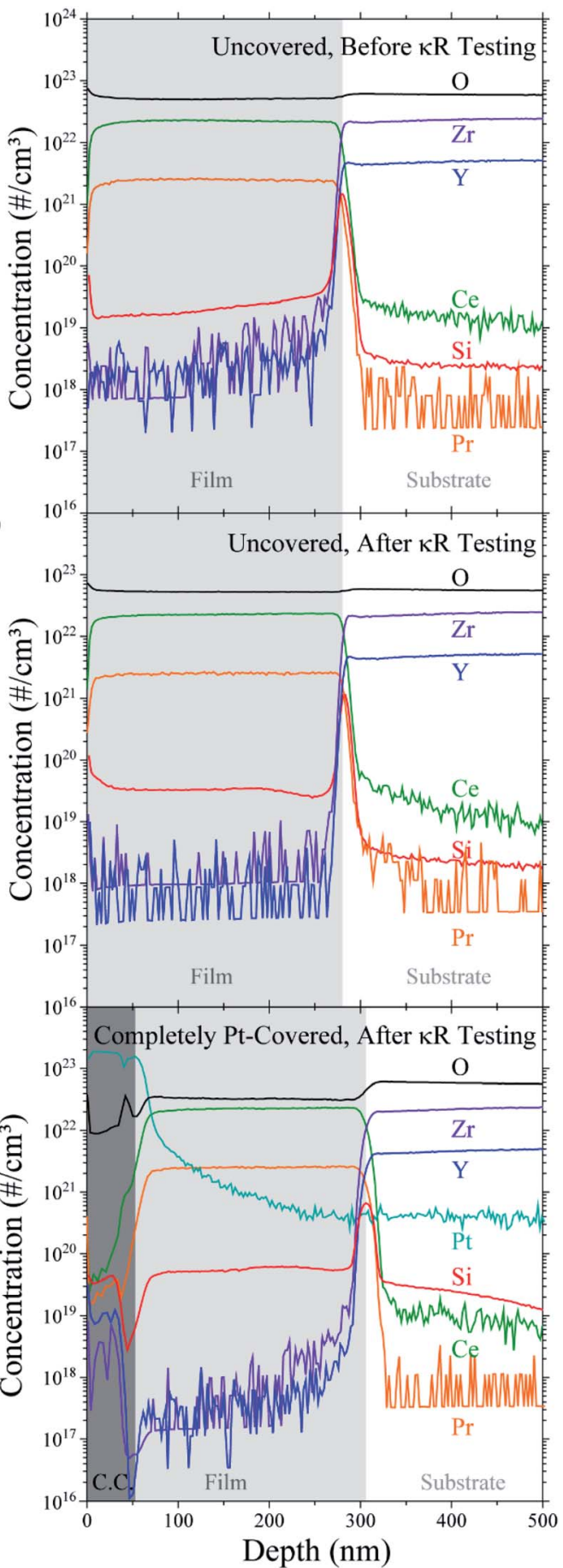

Fig. 8 SIMS analysis of (a) an uncovered PCOIYSZ sample after PLD and $1100{ }^{\circ} \mathrm{C}$ re-equilibration in air, (b) an uncovered PCO/YSZ sample after $\mathrm{PLD}, 1100^{\circ} \mathrm{C}$ re-equilibration in air, and $\kappa R$ testing, and (c) a completely Ptcovered PCO|YSZ sample after PLD, $1100{ }^{\circ} \mathrm{C}$ re-equilibration in air, Pt current collector (C.C) deposition, and $\kappa R$ testing. The position of the PCO-YSZ interface was determined from the intersection of the film and substrate majority cation concentrations (i.e. the $\mathrm{Ce}$ and the $\mathrm{Zr}$ concentrations). This position also corresponded to the midpoint in oxygen concentration between the film and substrate. The position of the current collector (C.C) - PCO interface in part C) was determined by the transition from a flat Pt concentration in the C.C. to a diffusion Pt concentration profile in the film. This C.C. - PCO interface location also produced identical near-surface reductions in the $\mathrm{Ce}$ and $\mathrm{Pr}$ film concentrations as those observed in the uncovered PCO films in parts (a) and (b). structure. Hence, it is likely that the $\sim 500{ }^{\circ} \mathrm{C}$ transition to a higher $k_{\text {chem }}$ activation energy upon cooling below $500{ }^{\circ} \mathrm{C}$ is related to a change in the rate-determining step for oxygen exchange brought about by the increased difficulty in exchanging oxygen as the thin film $\mathrm{PCO} \mathrm{Pr}^{3+} / \mathrm{Pr}^{4+}$ ratio and oxygen nonstocichometry rapidly trend toward zero below $\sim 500{ }^{\circ} \mathrm{C} .{ }^{75}$

Regardless of the exact reason for this newly-recognized $500{ }^{\circ} \mathrm{C}$ activation energy change, Fig. 6 makes it clear that completely covering the PCO surface with sputtered Pt dramatically boosts the measured $k_{\text {chem }}$. The fact that sputtered Pt did not reduce the measured $k_{\text {chem }}$ is consistent with the thin nature of the sputtered Pt current collectors, the low grain boundary and/or surface-path resistivities observed previously for oxygen transport in sputtered Pt films, ${ }^{64,104}$ and the likelypercolated $\sim 11 \%$ porosity of the sputtered $\mathrm{Pt}$ films ${ }^{78}$ facilitating gaseous oxygen transport to the PCO surface.

Fig. 6 also shows that the partially Pt-covered PCO|YSZ samples exhibited $k_{\text {chem }}$ values between those of the uncovered and completely Pt-covered PCO $\mid$ YSZ samples. With only $\sim 2.7 \%$ of the PCO surface covered by Pt, the observed $k_{\text {chem }}$ enhancements were modest and hence the partially Pt-covered PCO|YSZ samples could only be measured above $500{ }^{\circ} \mathrm{C}$, where they displayed activation energies similar to those measured previously.

Fig. 7 provides a graphical summary of just how much faster oxygen exchange was in the completely Pt-covered PCO|YSZ samples than in either the uncovered or partially Pt-covered PCO|YSZ samples. Specifically, even though the temperature for the completely Pt-covered PCO|YSZ curvature relaxation is $250{ }^{\circ} \mathrm{C}$ lower than the uncovered or partially Pt-covered PCO|YSZ samples in Fig. 6, the time required to complete the oxygen exchange process is $\sim 2$ times less.

Fig. 8 suggests that the platinum current collectors used here improved the PCO $k_{\text {chem }}$ by removing Si from the PCO surface and/or diffusing into the PCO. Specifically Fig. 8a and b show that the uncovered PCO films had approximately $1 \mathrm{Si}$ atom for every $100 \mathrm{Pr}$ atoms in their bulk and had enriched amounts of Si at their air-PCO and PCO-YSZ interfaces. This Si contamination probably resulted from the silica-based glassware used to produce the PCO powder utilized in PLD target fabrication (this contamination could likely have been avoided through the use of polyethylene beakers but was retained here to illustrate the interaction common processing and environmental contaminants can have with PCO platinum current collectors). Si enrichment at the air-PCO interface may help explain the low $k_{\text {chem }}$ values observed for the uncovered PCO|YSZ samples, since surface-segregated $\mathrm{Si}$ impurities are well-known for inhibiting oxygen surface exchange and bulk oxygen transport in PCO and a variety of other ceria-based compositions..$^{96,105-109}$ Fig. $8 \mathrm{a}$ and $\mathrm{b}$ also show a slight enhancement of $\mathrm{Zr}$ and Ce at the PCO surface, but since those elements occurred at concentrations 10 to 100 times less than the Si concentration, Si was assumed to be responsible for the low $k_{\text {chem }}$ values observed in the uncovered PCO|YSZ samples. Fig. 8a and b also show interdiffusion of $\mathrm{Pr}, \mathrm{Ce}, \mathrm{Zr}$, and $\mathrm{Y}$ between the film and substrate, and diffusion of $\mathrm{Si}$ from the film into the substrate, 
the majority of which presumably happened during the 1 hour, $1100{ }^{\circ} \mathrm{C}$ re-equilibration in air. Interestingly, a comparison of Fig. 8a and b shows that although the bulk Si level in the film and near the exposed surface roughly doubled (presumably due to silica vaporization from the silica $\kappa R$ test rig known to occur at and above $\left.\sim 600{ }^{\circ} \mathrm{C}\right)^{96,105}$ and some of the bulk Si migrated to the PCO $\mid$ YSZ interface, no other significant changes in the sample chemistry, or chemical distribution, occurred during $\kappa R$ testing up to $725^{\circ} \mathrm{C}$.

Fig. 8c suggests that the completely Pt-covered PCO $\mid \mathrm{YSZ}$ current collectors applied here cleaned the air-PCO interface by serving as a chemical getter for the surface-segregated $\mathrm{Si}, \mathrm{Zr}$ and Ce present on uncoated films. The ability of Pt current collectors to act as Si getters to improve the PCO $k_{\text {chem }}$ is not completely surprising since (1) Ma and Nicholas ${ }^{\mathbf{9}}$ recently quantified the relationship between the PCO Si surface content and $k_{\text {chem }}$, and (2) Zhao et al. ${ }^{\mathbf{1 0 5}}$ found that La or Sm PCO surface additions improved $k_{\text {chem }}$ by gettering surface Si. However, it is also possible that the near-surface dips in the $\mathrm{Si}, \mathrm{Zr}$, and Ce profiles could be artifacts caused by the SIMS front transitioning from the metal to the oxide.

In addition to suggesting that Pt cleared Si from the PCO surface, Fig. 8c shows that significant quantities of Pt diffused into the PCO film (with the Pt concentration exceeding the Pr doping level for more than $50 \mathrm{~nm}$ into the PCO film). This is somewhat surprising because the completely Pt-covered PCO|YSZ samples only saw temperatures up to $500{ }^{\circ} \mathrm{C}$ during $\kappa R$ testing. However, this behavior is consistent with prior reports that platinum can diffuse into ceria at room temperature, ${ }^{\mathbf{1 1 0}}$

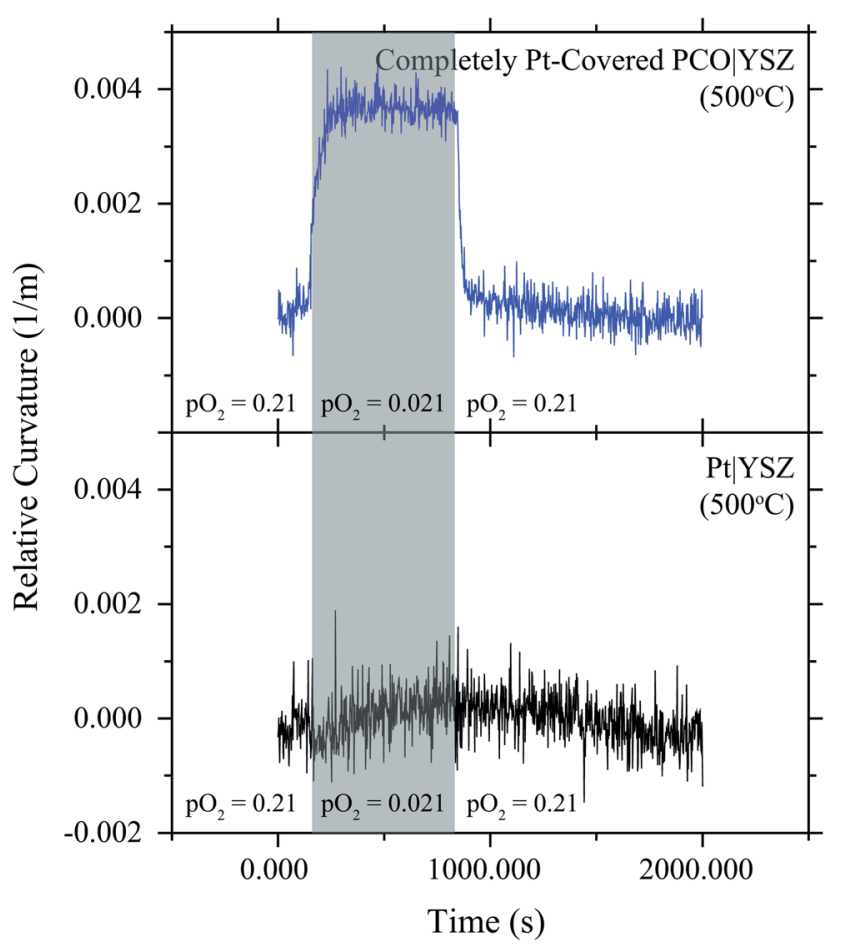

Fig. 9 Curvature changes upon $500{ }^{\circ} \mathrm{C} p_{\mathrm{O}_{2}}$ switching for (a) completely Pt-covered PCO|YSZ sample and (b) a completely Ptcovered YSZ wafer. especially when ceria experiences reducing conditions, ${ }^{\mathbf{1 1 1}}$ as likely occurred during the Pt current collector sputtering process.

Whether from the removal of Si from the PCO surface, Pt diffusion into the ceria, or some of the other mechanisms proposed in the literature, ${ }^{\mathbf{6 3 , 1 1 1 , 1 1 2}}$ the results here make it clear that completely covering a significant portion of a material's surface with $\mathrm{Pt}$ current-collectors can led to $k_{\text {chem }}$ values significantly different from those the material would display on its own. As such, the small $k_{\text {chem }}$ enhancements observed here for the partially Pt-covered samples in Fig. 6 were assumed to be due to the portion of the PCO close to the Pt current collectors behaving like the completely Pt-covered PCO|YSZ samples, while those portions of the PCO further away from the Pt current collectors behaved more like the uncoated PCO $\mid$ YSZ samples.

Fig. 9 compares the curvature response of a completely Ptcovered PCO|YSZ sample to a completely Pt-covered YSZ wafer. The fact that essentially no curvature response was observed in the completely Pt-covered YSZ wafer with $p_{\mathrm{O}_{2}}$ switching confirms that the observed $k_{\text {chem }}$ enhancements were not the result of oxygen exchange into/out of the bulk of the Pt, but instead were related to Pt current collectors influencing oxygen exchange into/out of the PCO.

\section{Conclusions}

Despite many studies suggesting that precious metal current collectors and/or impurities can impact the performance of oxygen-exchange-enabled devices, ${ }^{\mathbf{4 5}-48}$ precious metal current collectors are still routinely used to transport electronic species into/out of oxygen exchange materials in Electrical Conductivity Relaxation, ${ }^{36,49-58}$ and Electrical Impedance Spectroscopy ${ }^{59,60}$ oxygen exchange experiments. The results here demonstrate that precious metal current collectors are not necessarily inert (i.e. they can diffuse into and/or chemically clean the surface of the oxygen exchange material of interest), can unexpectedly alter the measured $k_{\text {chem }}$ values, and, hence, should be treated with caution when used for oxygen surface exchange measurements. This is especially true when performing oxygen exchange measurements on either bulk or thin film samples where a significant fraction of the oxygen-exchange-active surface is in close proximity to a precious metal current collector (such as ECR $k_{\text {chem }}$ measurements on materials with low electronic resistivities that require the close placement of interdigitated electrodes to get measurable electronic conductivities, experiments performed with fine-grained colloidal precious metal pastes and/or precious metal thin films applied over most of the oxygen-exchanging surface, etc.). Further, if precious metal current collectors dramatically improve the oxygen exchange kinetics of the neighboring/underlying MIEC, artificially high $k_{\text {chem }}$ values could also be recorded for electrical (ECR, EIS, etc.) $k_{\text {chem }}$ measurements performed using small precious metal current collectors placed a significant distance apart (since the precious-metal-activated portions of the MIEC surface would act as "major leaks" for oxygen incorporation into the bulk of the material and hence would "drown-out" the 
response from slower oxygen incorporation along the bare MIEC surfaces). For all these reasons, it is likely that precious metal current collectors are responsible for a significant portion of the $k_{\text {chem }}$ variation reported in the literature for "identical" materials tested under "identical" conditions.

\section{Author contributions}

Y. Ma performed the thin film deposition and characterization, T. E. Burye performed the $k_{\text {chem }}$ literature review, and J. D. Nicholas conceptualized and led the write-up of this work.

\section{Conflicts of interest}

There are no conflicts to declare.

\section{Acknowledgements}

Y. Ma acknowledges support from U.S. Department of Energy Office of Fossil Energy Award Number DE-FE0031672. T. E. Burye and J.D. Nicholas acknowledge support from U.S. National Science Foundation CAREER Award Number CBET1254453. The PLD thin films were grown at the Materials Research Center at Northwestern University, which is supported by the National Science Foundation MRSEC program (DMR1720139) and the Soft and Hybrid Nanotechnology Experimental (SHyNE) Resource (NSF ECCS-1542205). Scanning electron microscopy was conducted at the Michigan State University Composite Materials and Structures Center, which is supported by the NSF Major Research Instrumentation Program and Michigan State University.

\section{References}

1 E. D. Wachsman and K. T. Lee, Science, 2011, 334, 935-939.

2 S. McIntosh and R. J. Gorte, Chem. Rev., 2004, 104, 48454865.

3 S. H. Chan, C. F. Low and O. L. Ding, J. Power Sources, 2002, 103, 188-200.

4 J. D. Nicholas, ECS Interface, 2013, 22, 49-54.

5 C. Graves, S. D. Ebbesen, M. Mogensen and K. S. Lackner, Renewable Sustainable Energy Rev., 2011, 15, 1-23.

6 M. B. Mogensen, M. Chen, H. L. Frandsen, C. Graves, J. B. Hansen, K. V. Hansen, A. Hauch, T. Jacobsen, S. H. Jensen, T. L. Skafte and X. Sun, Clean Energy, 2019, 3, 175-201.

7 M. Hecht, J. Hoffman, D. Rapp, J. McClean, J. SooHoo, R. Schaefer, A. Aboobaker, J. Mellstrom, J. Hartvigsen, F. Meyen, E. Hinterman, G. Voecks, A. Liu, M. Nasr, J. Lewis, J. Johnson, C. Guernsey, J. Swoboda, C. Eckert, C. Alcalde, M. Poirier, P. Khopkar, S. Elangovan, M. Madsen, P. Smith, C. Graves, G. Sanders, K. Araghi, M. D. Juarez, D. Larsen, J. Agui, A. Burns, K. Lackner, R. Nielsen, T. Pike, B. Tata, K. Wilson, T. Brown, T. Disarro, R. Morris, R. Steinkraus, R. Surampudi, T. Werne and A. Ponce, Space Sci. Rev., 2021, 217, 76.
8 Y. Zhang and J. D. Nicholas, J. Electrochem. Soc., 2021, 168, 034513.

9 J. Crank, The Mathematics of Diffusion, Oxford University Press, London, 2nd edn, 1975.

$10 \mathrm{~J}$. Hayd, H. Yokokawa and E. Ivers-Tiffee, J. Electrochem. Soc., 2013, 160, F351-F359.

11 J. Maier, Physical Chemistry of Ionic Materials: Ions and Electrons in Solids, John Wiley \& Sons, West Sussex, England, 2004.

12 F. S. Baumann, J. Fleig, H.-U. Habermeier and J. Maier, Solid State Ionics, 2006, 177, 1071-1081.

13 B. T. Dalslet, M. Søgaard and P. V. Hendriksen, J. Electrochem. Soc., 2007, 154, B1276-B1287.

14 J. Maier, Solid State Ionics, 1998, 112, 197-228.

$15 \mathrm{~J}$. E. tenElshof, M. H. R. Lankhorst and H. J. M. Bouwmeester, J. Electrochem. Soc., 1997, 144, 1060-1067.

16 S. B. Adler, J. A. Lane and B. C. H. Steele, J. Electrochem. Soc., 1996, 143, 3554-3564.

17 C. W. Tanner, K.-Z. Fung and A. V. Virkar, J. Electrochem. Soc., 1997, 144, 21-30.

18 M. Shah, J. D. Nicholas and S. A. Barnett, Electrochem. Commun., 2009, 11, 2-5.

19 J. D. Nicholas, L. Wang, A. V. Call and S. A. Barnett, Phys. Chem. Chem. Phys., 2012, 14, 15379-15392.

20 J. D. Nicholas and S. A. Barnett, J. Electrochem. Soc., 2010, 157, B536-B541.

21 J. D. Nicholas and S. A. Barnett, J. Electrochem. Soc., 2009, 156, B458-B464.

22 X. Song, A. Diaz, A. Benard and J. Nicholas, Struct. Multidiscip. Optim., 2013, 47, 453-464.

23 W. C. Chueh, C. Falter, M. Abbott, D. Scipio, P. Furler, S. M. Haile and A. Steinfeld, Science, 2010, 330, 1797-1801.

24 T. Heisig, C. Baeumer, U. N. Gries, M. P. Mueller, C. La Torre, M. Luebben, N. Raab, H. Du, S. Menzel, D. N. Mueller, C.-L. Jia, J. Mayer, R. Waser, I. Valov, R. A. De Souza and R. Dittmann, Adv. Mater., 2018, 30, 1800957.

25 H. J. M. Bouwmeester, Catal. Today, 2003, 82, 141-150.

26 A. Trovarelli, Catal. Rev.: Sci. Eng., 1996, 38, 439-509.

27 M. W. Ahn, K. S. Park, J. H. Heo, J. G. Park, D. W. Kim, K. J. Choi, J. H. Lee and S. H. Hong, Appl. Phys. Lett., 2008, 93, 263103.

28 J. Januschewsky, M. Ahrens, A. Opitz, F. Kubel and J. Fleig, Adv. Funct. Mater., 2009, 19, 3151-3156.

29 D. Tripkovic, R. Kungas, M. B. Mogensen and P. V. Hendriksen, J. Mater. Chem. A, 2019, 7, 11782-11791.

30 E. Navickas, T. M. Huber, Y. Chen, W. Hetaba, G. Holzlechner, G. Rupp, M. Stoeger-Pollach, G. Friedbacher, H. Hutter, B. Yildiz and J. Fleig, Phys. Chem. Chem. Phys., 2015, 17, 7659-7669.

31 K. Kerman, C. Ko and S. Ramanathan, Phys. Chem. Chem. Phys., 2012, 14, 11953-11960.

32 L. Zhang, S. Wang, H. Huang, Y. Li, Y. Lu and C. Xia, J. Electrochem. Soc., 2017, 164, F610-F615. 
33 M. Burriel, H. Téllez, R. J. Chater, R. Castaing, P. Veber, M. Zaghrioui, T. Ishihara, J. A. Kilner and J.-M. Bassat, J. Phys. Chem. C, 2016, 120, 17927-17938.

34 S. P. Waldow, B. J. Statham, H. F. Wardenga, T. E. Weirich, A. Klein and R. A. De Souza, ACS Appl. Mater. Interfaces, 2020, 12, 36768-36777.

35 R. A. Cox-Galhotra and S. McIntosh, Solid State Ionics, 2010, 181, 1429-1436.

36 D. Tripkovic, R. Kungas, M. B. Mogensen and P. V. Hendriksen, Phys. Chem. Chem. Phys., 2020, 22, 15418-15426.

37 Y. Cheng, A. S. Raman, J. Paige, L. Zhang, D. Y. Sun, M. U. Chen, A. Vojvodic, R. J. Gorte and J. M. Vohs, J. Phys. Chem. Lett., 2019, 10, 4082-4088.

38 C. Argirusis, S. Wagner, W. Menesklou, C. Warnke, T. Damjanovic, G. Borchardt and E. Ivers-Tiffée, Phys. Chem. Chem. Phys., 2005, 7, 3523-3525.

39 Y. Cao, M. J. Gadre, A. T. Ngo, S. B. Adler and D. D. Morgan, Nat. Commun., 2019, 10, 1346.

40 M. Siebenhofer, T. M. Huber, G. Friedbacher, W. Artner, J. Fleig and M. Kubicek, J. Mater. Chem. A, 2020, 8, 79687979.

41 E. Bucher, W. Sitte, F. Klauser and E. Bertel, Solid State Ionics, 2012, 208, 43-51.

42 Ø. F. Lohne, M. Søgaard and K. Wiik, J. Electrochem. Soc., 2013, 160, F1282-F1292.

43 W. Preis, E. Bucher and W. Sitte, J. Power Sources, 2002, 106, 116-121.

44 A. Falkenstein, D. N. Mueller, R. A. De Souza and M. Martin, Solid State Ionics, 2015, 280, 66-73.

45 J. Zheng, X. Wang, J. Yu and N. Tian, Mater. Res. Express, 2021, 8, 035502.

46 H. Uchida, M. Yoshida and M. Watanabe, J. Electrochem. Soc., 1999, 146, 1-7.

47 M. Cargnello, V. V. T. Doan-Nguyen, T. R. Gordon, R. E. Diaz, E. A. Stach, R. J. Gorte, P. Fornasiero and C. B. Murray, Science, 2013, 341, 771-773.

48 H. G. Seo, Y. Choi and W. Jung, Adv. Energy Mater., 2018, 8, 1703647.

49 R. Gao, A. Fernandez, T. Chakraborty, A. L. Luo, D. Pesquera, S. Das, G. Velarde, V. Thoreton, J. Kilner, T. Ishihara, S. Nemsak, E. J. Crumlin, E. Ertekin and L. W. Martin, Adv. Mater., 2021, 33, 2100977.

50 G. Yang, S.-Y. Kim, C. Sohn, J. K. Keum and D. Lee, J. Appl. Sci., 2021, 11, 3778.

51 C. Nicollet, D. Kalaev and H. L. Tuller, Solid State Ionics, 2019, 331, 96-101.

52 R. A. Cox-Galhotra and S. McIntosh, Solid State Ionics, 2012, 228, 14-18.

53 M. Søgaard, A. Bieberle-Hutter, P. V. Hendriksen, M. Mogensen and H. L. Tuller, J. Electroceram., 2011, 27, 134-142.

54 L. Yan, K. R. Balasubramaniam, S. Wang, H. Du and P. A. Salvador, Solid State Ionics, 2011, 194, 9-16.

55 A. Zomorrodian, H. Salamati, Z. G. Lu, X. Chen, N. J. Wu and A. Ignatiev, Int. J. Hydrogen Energy, 2010, 35, 1244312448.
56 M. Burriel, C. Niedrig, W. Menesklou, S. F. Wagner, J. Santiso and E. Ivers-Tiffée, Solid State Ionics, 2010, 181, 602-608.

57 M. Mosleh, M. Søgaard and P. V. Hendriksen, J. Electrochem. Soc., 2009, 156, B441-B457.

58 X. Chen, S. Wang, Y. L. Yang, L. Smith, N. J. Wu, B. I. Kim, S. S. Perry, A. J. Jacobson and A. Ignatiev, Solid State Ionics, 2002, 146, 405-413.

59 N. H. Perry, J. J. Kim and H. L. Tuller, Sci. Technol. Adv. Mater., 2018, 19, 130-141.

60 P. Plonczak, M. Søgaard, A. Bieberle-Hütter, P. V. Hendriksen and L. J. Gauckler, J. Electrochem. Soc., 2012, 159, B471-B482.

61 P. Simons, H. I. Ji, T. C. Davenport and S. M. Haile, J. Am. Ceram. Soc., 2017, 100, 1161-1171.

62 N. J. Simrick, A. Bieberle-Hutter, T. M. Ryll, J. A. Kilner, A. Atkinson and J. L. M. Rupp, Solid State Ionics, 2012, 206, 7-16.

63 A. K. Opitz, A. Schintlmeister, H. Hutter and J. Fleig, Phys. Chem. Chem. Phys., 2010, 12, 12734-12745.

64 A. K. Opitz, A. Lutz, M. Kubicek, F. Kubel, H. Hutter and J. Fleig, Electrochim. Acta, 2011, 56, 9727-9740.

65 A. Bruix, A. Migani, G. N. Vayssilov, K. M. Neyman, J. Libuda and F. Illas, Phys. Chem. Chem. Phys., 2011, 13, 1138411392.

66 H. Baker and H. Okamoto, ASM Handbook, Vol 03-Alloy Phase Diagrams, 1992.

67 Y. Zhang, Y. Wen, K. Huang and J. D. Nicholas, ACS Appl. Energy Mater., 2020, 3, 4057-4067.

68 S. P. Jiang and J. G. Love, Solid State Ionics, 2003, 158, 45-53.

69 M. Rohnke, K. Schaepe, A. K. Bachmann, M. Laenger and J. Janek, Appl. Surf. Sci., 2017, 422, 817-827.

70 M. Chanthanumataporn, T. Nagasawa and K. Hanamura, J. Electrochem. Soc., 2019, 166, F581-F586.

71 V. A. C. Haanappel, D. Rutenbeck, A. Mai, S. Uhlenbruck, D. Sebold, H. Wesemeyer, B. Röwekamp, C. Tropartz and F. Tietz, J. Power Sources, 2004, 130, 119-128.

72 A. Egger and W. Sitte, Solid State Ionics, 2014, 258, 30-37.

73 M. Sahibzada, S. J. Benson, R. A. Rudkin and J. A. Kilner, Solid State Ionics, 1998, 113-115, 285-290.

74 C. Riedl, A. Schmid, A. Nenning, H. Summerer, S. Smetaczek, S. Schwarz, J. Bernardi, A. Optiz, A. Limbeck and J. Fleig, J. Electrochem. Soc., 2020, 167, 104514.

75 Y. Ma and J. D. Nicholas, Phys. Chem. Chem. Phys., 2018, 20, 27350-27360.

76 E. J. Skiba, T. Chen and N. H. Perry, ACS Appl. Mater. Interfaces, 2020, 12, 48614-48630.

77 L. A. Chick, L. R. Pederson, G. D. Maupin, J. L. Bates, L. E. Thomas and G. J. Exarhos, Mater. Lett., 1990, 10, 6-12.

78 I. Chang, S. Woo, M. H. Lee, J. H. Shim, Y. Piao and S. W. Cha, Appl. Surf. Sci., 2013, 282, 463-466.

79 Q. Yang, T. E. Burye, R. R. Lunt and J. D. Nicholas, Solid State Ionics, 2013, 249-250, 123-128.

80 Q. Yang and J. D. Nicholas, J. Electrochem. Soc., 2014, 161, F3025-F3031.

81 J. D. Nicholas, Extreme Mechanics Letters, 2016, 9, 405-421. 
82 J. D. Nicholas, in Electro-Chemo-Mechanics of Solids, ed. S. Bishop, D. Marrocchelli, N. Perry and B. Sheldon, Springer, New York, 2017, DOI: 10.1007/978-3-319-514079_5, ch. 5, pp. 103-136.

83 D. Chen, S. R. Bishop and H. L. Tuller, Chem. Mater., 2014, 26, 6622-6627.

84 J. Sheth, D. Chen, J. J. Kim, W. J. Bowman, P. A. Crozier, H. L. Tuller, S. T. Misture, S. Zdzieszynski, B. W. Sheldon and S. R. Bishop, Nanoscale, 2016, 8, 16499-16510.

85 S. R. Bishop, H. L. Tuller, Y. Kuru and B. Yildiz, J. Eur. Ceram. Soc., 2011, 31, 2351-2356.

86 G. Kim, S. Wang, A. J. Jacobson and C. L. Chen, Solid State Ionics, 2006, 177, 1461-1467.

87 C. H. Ko, A. Karthikeyan and S. Ramanathan, J. Chem. Phys., 2011, 134, 014704.

88 G. Kim, S. Wang, A. J. Jacobson, Z. Yuan, W. Donner, C. L. Chen, L. Reimus, P. Brodersen and C. A. Mims, Appl. Phys. Lett., 2006, 88, 024103.

89 M. W. den Otter, H. J. M. Bouwmeester, B. A. Boukamp and H. Verweij, J. Electrochem. Soc., 2001, 148, J1-J6.

90 D. Chen, S. R. Bishop and H. L. Tuller, J. Electroceram., 2012, 28, 62-69.

91 N. Savvides, A. Thorley, S. Gnanarajan and A. Katsaros, Thin Solid Films, 2001, 388, 177-182.

92 C.-M. Wang, S. Thevuthasan and C. H. F. Peden, J. Am. Ceram. Soc., 2003, 86, 363-365.

93 D. Q. Shi, M. Ionescu, J. McKinnon and S. X. Dou, Physica C, 2001, 356, 304-310.

94 N. L. Edleman, A. Wang, J. A. Belot, A. W. Metz, J. R. Babcock, A. M. Kawaoka, J. Ni, M. V. Metz, C. J. Flaschenriem, C. L. Stern, L. M. Liable-Sands, A. L. Rheingold, P. R. Markworth, R. P. H. Chang, M. P. Chudzik, C. R. Kannewurf and T. J. Marks, Inorg. Chem., 2002, 41, 5005-5023.

95 A. Cavallaro, F. Sandiumenge, J. Gazquez, T. Puig, X. Obradors, J. Arbiol and H. C. Freyhardt, Adv. Funct. Mater., 2006, 16, 1363-1372.

96 Y. Ma and J. D. Nicholas, J. Electrochem. Soc., 2021, 168, 104518.

97 A. G. Shard, Surf. Interface Anal., 2014, 46, 175-185.

98 Y. Wang, K. Duncan, E. D. Wachsman and F. Ebrahimi, Solid State Ionics, 2007, 178, 53-58.

99 A. Martínez-Amesti, A. Larrañaga, L. M. RodríguezMartínez, M. L. Nó, J. L. Pizarro, A. Laresgoiti and M. I. Arriortua, J. Power Sources, 2009, 192, 151-157.

100 P. P. Dholabhai, J. B. Adams, P. Crozier and R. Sharma, J. Chem. Phys., 2010, 132, 094104.

101 H. L. Tuller and A. S. Nowick, J. Phys. Chem. Solids, 1977, 38, 859-867.

102 T. Chen, G. F. Harrington, J. Masood, K. Sasaki and N. H. Perry, ACS Appl. Mater. Interfaces, 2019, 11, 91029116.

103 P. S. Manning, J. D. Sirman and J. A. Kilner, Solid State Ionics, 1997, 93, 125-132.

104 T. M. Huber, A. K. Opitz and J. Fleig, Solid State Ionics, 2015, 273, 8-12.
105 L. Zhao, N. H. Perry, T. Daio, K. Sasaki and S. R. Bishop, Chem. Mater., 2015, 27, 3065-3070.

106 D. Pérez-Coll, P. Núñez and J. R. Frade, J. Power Sources, 2011, 196, 8383-8390.

107 T. S. Zhang, J. Ma, Y. J. Leng, S. H. Chan, P. Hing and J. A. Kilner, Solid State Ionics, 2004, 168, 187-195.

108 Y. H. Cho, P. S. Cho, G. Auchterlonie, D. K. Kim, J. H. Lee, D. Y. Kim, H. M. Park and J. Drennan, Acta Mater., 2007, 55, 4807-4815.

109 T. S. Zhang, J. Ma, S. H. Chan, P. Hing and J. A. Kilner, Solid State Sci., 2004, 6, 565-572.

110 Y. Zhou, M. Nakashima and J. M. White, J. Phys. Chem., 1988, 92, 812-818.

111 P. Luches, G. Gasperi, M. Sauerbrey, S. Valeri, J. Falta and J. I. Flege, Front. Chem., 2019, 7, 57.

112 W. Yang, Z. Wang, Z. Wang, Z. Yang, C. Xia, R. Peng, X. Wu and Y. Lu, ACS Appl. Mater. Interfaces, 2014, 6, 21051-21059.

113 M. Søgaard, P. Vang Hendriksen and M. Mogensen, J. Solid State Chem., 2007, 180, 1489-1503.

114 E. N. Armstrong, K. L. Duncan and E. D. Wachsman, Phys. Chem. Chem. Phys., 2013, 15, 2298-2308.

115 T. Ishigaki, S. Yamauchi, K. Kishio, J. Mizusaki and K. Fueki, J. Solid State Chem., 1988, 73, 179-187.

116 F. S. Baumann, J. Fleig, G. Cristiani, B. Stuhlhofer, H. U. Habermeier and J. Maier, J. Electrochem. Soc., 2007, 154, B931-B941.

117 H. J. M. Bouwmeester, M. W. Den Otter and B. A. Boukamp, J. Solid State Electrochem., 2004, 8, 599-605.

118 Y. L. Huang, C. Pellegrinelli, K. T. Lee, A. Perel and E. D. Wachsman, J. Electrochem. Soc., 2015, 162, F965-F970.

119 J. A. Lane, S. J. Benson, D. Waller and J. A. Kilner, Solid State Ionics, 1999, 121, 201-208.

120 Y. H. Li, K. Gerdes, T. Horita and X. B. Liu, J. Electrochem. Soc., 2013, 160, F343-F350.

121 P. Ried, P. Holtappels, A. Wichser, A. Ulrich and T. Graule, J. Electrochem. Soc., 2008, 155, B1029-B1035.

122 S. Wang, P. A. W. van der Heide, C. Chavez, A. J. Jacobson and S. B. Adler, Solid State Ionics, 2003, 156, 201-208.

123 R. J. Chater, S. Carter, J. A. Kilner and B. C. H. Steele, Solid State Ionics, 1992, 53, 859-867.

124 B. C. H. Steele and J. M. Bae, Solid State Ionics, 1998, 106, 255-261.

125 R. Moreno, J. Zapata, J. Roqueta, N. Bagués and J. Santiso, J. Electrochem. Soc., 2014, 161, F3046-F3051.

126 A. V. Berenov, A. Atkinson, J. A. Kilner, E. Bucher and W. Sitte, Solid State Ionics, 2010, 181, 819-826.

127 A. Egger, E. Bucher, M. Yang and W. Sitte, Solid State Ionics, 2012, 225, 55-60.

128 M. Søgaard, P. V. Hendriksen, M. Mogensen, F. W. Poulsen and E. Skou, Solid State Ionics, 2006, 177, 3285-3296.

129 S. B. Adler, Solid State Ionics, 1998, 111, 125-134.

130 T. C. Yeh, J. L. Routbort and T. O. Mason, Solid State Ionics, 2013, 232, 138-143.

131 I. C. Fullarton, J. P. Jacobs, H. E. van Benthem, J. A. Kilner, H. H. Brongersma, P. J. Scanlon and B. C. H. Steele, Ionics, 1995, 1, 51-58. 
132 Y.-P. Fu, J. Ouyang, C.-H. Li and S.-H. Hu, J. Power Sources, 2013, 240, 168-177.

133 L. Wang, R. Merkle, J. Maier, T. Acarturk and U. Starke, Appl. Phys. Lett., 2009, 94, 071908.

134 E. Bucher, A. Egger, G. B. Caraman and W. Sitte, J. Electrochem. Soc., 2008, 155, B1218.

135 E. Bucher, A. Egger, P. Ried, W. Sitte and P. Holtappels, Solid State Ionics, 2008, 179, 1032-1035.

136 D. Chen and Z. Shao, Int. J. Hydrogen Energy, 2011, 36, 6948-6956.
137 E. Girdauskaite, H. Ullmann, V. V. Vashook, U. Guth, G. B. Caraman, E. Bucher and W. Sitte, Solid State Ionics, 2008, 179, 385-392.

138 F. S. Baumann, J. Fleig, H. U. Habermeier and J. Maier, Solid State Ionics, 2006, 177, 3187-3191.

139 L. Wang, R. Merkle and J. Maier, J. Electrochem. Soc., 2010, 157, B1802-B1808.

140 Ø. F. Lohne, M. Søgaard and K. Wiik, J. Electrochem. Soc., 2013, 160, F1282-F1292.

141 C. Nicollet, C. Toparli, G. F. Harrington, T. Defferriere, B. Yildiz and H. L. Tuller, Nat. Catal., 2020, 3, 913-920. 